\title{
Trigeminal Ganglion Innervates the Auditory Brainstem
}

\author{
SUSAN E. SHORE, ${ }^{1,2 *}$ ZOLTAN VASS, ${ }^{3}$ NOEL L. WYS,${ }^{1}$ AND \\ RICHARD A. ALTSCHULER ${ }^{1}$ \\ ${ }^{1}$ Kresge Hearing Research Institute, University of Michigan, Ann Arbor, \\ Michigan 48109-0506 \\ ${ }^{2}$ Department of Otolaryngology, Medical College of Ohio, Toledo, Ohio 43699 \\ ${ }^{3}$ Department of Otolaryngology, Albert Szent-Gyorgyi Medical University,
} Szeged, Hungary

\begin{abstract}
A neural connection between the trigeminal ganglion and the auditory brainstem was investigated by using retrograde and anterograde tract tracing methods: iontophoretic injections of biocytin or biotinylated dextran-amine (BDA) were made into the guinea pig trigeminal ganglion, and anterograde labeling was examined in the cochlear nucleus and superior olivary complex. Terminal labeling after biocytin and BDA injections into the ganglion was found to be most dense in the marginal cell area and secondarily in the magnocellular area of the ventral cochlear nucleus (VCN). Anterograde and retrograde labeling was also seen in the shell regions of the lateral superior olivary complex and in periolivary regions. The labeling was seen in the neuropil, on neuronal somata, and in regions surrounding blood vessels. Retrograde labeling was investigated using either wheatgerm agglutininhorseradish peroxidase (WGA-HRP), BDA, or a fluorescent tracer, iontophoretically injected into the VCN. Cells filled by retrograde labeling were found in the ophthalmic and mandibular divisions of the trigeminal ganglion. We have previously shown that these divisions project to the cochlea and middle ear, respectively. This study provides the first evidence that the trigeminal ganglion innervates the cochlear nucleus and superior olivary complex. This projection from a predominantly somatosensory ganglion may be related to integration mechanisms involving the auditory end organ and its central targets. J. Comp. Neurol. 419: 271-285, 2000. ๑ 2000 Wiley-Liss, Inc.
\end{abstract}

Indexing terms: pathways; cochlear nucleus; lateral superior olivary complex; olivocochlear; somatosensory

It is well established that somatosensory stimuli evoke responses in auditory neurons (Aitkin et al., 1978, 1981). Such multisensory integration may play a role in localizing the body in space, once attributed only to higher centers such as the superior colliculus where auditory, somatosensory, and visual inputs converge (Drager and Hubel, 1976; Chalupa and Rhoades, 1977). The trigeminal system is one major component of this integration, contributing a major source of somatosensory input to the superior colliculus from the brainstem trigeminal complex (Killackney and Erzurumlu, 1981). More recent neuroanatomical data indicate that somatosensory and auditory information converge at more peripheral sites. First-order relay somatosensory neurons, which subserve tactile and kinesthetic sensations, send direct projections to the cochlear nucleus: for example, the dorsal column nuclei and interpolar and caudal spinal trigeminal nuclei send fibers directly to the dorsal cochlear nucleus (DCN) and the granule cell region of the ventral cochlear nucleus (Itoh et al., 1987; Weinberg and Rustioni, 1987). A projection from the cuneate nucleus gives rise to mossy fiber terminals in the dorsal DCN and granule cell domains of the cochlear nucleus (Wright and Ryugo, 1996). These projections may be excitatory or inhibitory (Saade et al., 1989; Young et al., 1995) as demonstrated by electrical stimulation and tac-

\footnotetext{
Grant sponsor: NIH; Grant numbers: 5RO1DC00383, RO1 DC 000105; Grant sponsor: National Organization of Hearing Research (NOHR); Grant sponsor: Fogerty International; Grant number: TW 00502.

*Correspondence to: S.E. Shore, Ph.D., Kresge Hearing Research Institute, University of Michigan, 1301 E. Ann St., Ann Arbor, MI 48109. E-mail: Sushore@umich.edu

Received 2 August 1999; Revised 2 November 1999; Accepted 2 December 1999
} 
tile manipulation of the pinna (Young et al., 1995). Because changes in pinna position provide important spectral cues for sound localization (Rice et al., 1992), somatosensory input to the cochlear nucleus regarding pinna position may aid in sound localization performed by DCN cells. Somatosensory innervation of the cochlear nucleus or superior olivary complex may also be involved in mechanisms related to neck movements, which play a role in orientation to acoustic stimuli.

The present investigation demonstrates that secondorder auditory neurons in the cochlear nucleus are innervated by both the ophthalmic and mandibular divisions of the trigeminal ganglion, which also project to the cochlea and middle ear, respectively (Vass et al., 1997, 1998b). The ophthalmic division of the trigeminal ganglion also innervates the extraocular muscles (Aigner et al., 1997), raising the interesting possibility of interactions among these three systems. A second major finding indicates that a reciprocal connection exists between neurons in the shell regions of the lateral superior olivary complex and the trigeminal ganglion. Together with the trigeminal ganglion innervation of the small cell cap region of the anteroventral cochlear nucleus (AVCN), this projection may form part of the olivocochlear feedback system.

\section{MATERIALS AND METHODS}

All experiments were carried out in accordance with the NIH Guide For the Care and Use of Laboratory Animals. Twelve pigmented guinea pigs (250-350 g; NIH Outbred strain, Murphy Breeding Laboratory, Plainfield, IN) were used in this study. The guinea pigs were anesthetized with ketamine hydrochloride (Ketaset; $80 \mathrm{mg} / \mathrm{kg}$ ) and xylazine (Rompun; $4 \mathrm{mg} / \mathrm{kg}$ ) and placed in a stereotaxic frame (David Kopf, Tujunga, CA), then a longitudinal incision was made in the scalp. Periodic drug supplements were used to maintain anesthetic levels throughout the procedure.

\section{Abbreviations}

$\begin{array}{ll}\text { AVCN } & \text { anteroventral cochlear nucleus } \\ \text { AVII } & \text { accessory facial nucleus } \\ \text { BDA } & \text { biotinylated dextran amine } \\ \text { DAB } & 3,3^{\prime} \text {-diaminobenzidine tetrahydrochloride } \\ \text { DCN } & \text { dorsal cochlear nucleus } \\ \text { LNTB } & \text { lateral nucleus of the trapezoid body } \\ \text { LPO } & \text { lateral periolivary region } \\ \text { LSO } & \text { lateral superior olivary complex } \\ \text { Mand } & \text { mandibular division } \\ \text { Max } & \text { maxillary division } \\ \text { MSO } & \text { medial superior olivary complex } \\ \text { MTB } & \text { medial nucleus of the trapezoid body } \\ \text { M5 } & \text { motor nucleus of the fifth cranial (trigeminal) nerve } \\ \text { OCA } & \text { octopus cell area } \\ \text { Oph } & \text { ophthalmic division } \\ \text { PN } & \text { pontine nucleus } \\ \text { PR5 } & \text { principal trigeminal nucleus } \\ \text { PVCN } & \text { posteroventral cochlear nucleus } \\ \text { RN } & \text { raphe nucleus } \\ \text { RPO } & \text { rostral periolivary region } \\ \text { R7 } & \text { root of the 7th cranial nerve } \\ \text { SCC } & \text { small cell cap of the VCN } \\ \text { ST5 } & \text { spinal trigeminal nucleus } \\ \text { TZ } & \text { trapezoid body } \\ \text { VCN } & \text { ventral cochlear nucleus } \\ \text { VNTB } & \text { ventral nucleus of the trapezoid body } \\ \text { WGA-HRP } & \text { wheatgerm agglutinin-horseradish peroxidase } \\ & \end{array}$

\section{Anterograde tracing}

Injections using biocytin and BDA. Biocytin and biotinylated dextran-amine (BDA) injections were made into the trigeminal ganglion, and anterograde labeling was examined in the cochlear nucleus, a light microscopic evaluation in five animals and an electron microscopic evaluation in two animals. The location of the trigeminal ganglion was identified by using stereotaxic coordinates (0.37 $\mathrm{cm}$ caudal to bregma, $0.45 \mathrm{~cm}$ lateral from midline, $1.3 \mathrm{~cm}$ ventral to bregma), a small hole was drilled in the skull without disturbing the meninges, and a glass micropipette (tip diameter $25-30 \mu \mathrm{m}$ ) was lowered $13 \mathrm{~mm}$ by micromanipulator into the left trigeminal ganglion. Iontophoretic injections of biocytin or BDA were delivered via a glass microelectrode by using a constant current generator (Stoelting, $3 \mu \mathrm{A}$ alternating for 20 minutes). Biocytin (Sigma Chemical Co., St. Louis, MO; B-4261) was prepared as a $5 \%$ solution in $0.05 \mathrm{M}$ Tris buffer $(\mathrm{pH} 7.6)$. The solution could be stored at $4^{\circ} \mathrm{C}$ for up to 7 days with no noticeable loss of activity. Dental cement was used to seal the opening, the overlying skin was sutured, and the animals were allowed to recover.

Light microscopic assessment. Twenty-four hours after the biocytin and 4-6 days after BDA injections, animals were euthanized. Each guinea pig was anesthetized with nembutal (15 mg/kg, i.p.) and ketamine (40 $\mathrm{mg} / \mathrm{kg}, \mathrm{i} . \mathrm{m}$.) and perfused through the left ventricle of the heart with $200 \mathrm{ml}$ of $0.1 \mathrm{M} \mathrm{pH} 7.4$ phosphate buffer, followed by $200 \mathrm{ml}$ of $1 \%$ paraformaldehyde and $1.5 \%$ glutaraldehyde in $0.1 \mathrm{M}$ phosphate buffer, $\mathrm{pH}$ 7.2-7.4. The flow of the fixative to the trigeminal ganglia and brainstem by way of the common carotid arteries was maximized by occluding the brachial arteries and the descending aorta. Following perfusion-fixation, both the brain and trigeminal ganglia were isolated and placed in fresh fixative (2\% paraformaldehyde and $2.5 \%$ glutaraldehyde in $0.1 \mathrm{M}$ phosphate buffer, $\mathrm{pH} 7.2-7.4$ ) for $2-4$ hours at $4^{\circ} \mathrm{C}$. The tissues were then incubated overnight at $4^{\circ} \mathrm{C}$ with $30 \%$ sucrose in $0.1 \mathrm{M}$ phosphate buffer.

Each specimen was frozen with dry ice in $100 \%$ ethanol and frozen transverse sections obtained serially at $30-\mu \mathrm{m}$ increments on a sliding microtome. For BDA and biocytin, the sections were first incubated for 2 hours in Avidin-Dhorseradish peroxidase (HRP; Vector Laboratories, Inc., Burlingame, CA; \#A-2004), in 0.1 M phosphate buffer with 1\% Triton X-100 (Sigma 9002-93-1), pH 7.4, and then reacted with $3,3^{1}$-diaminobenzidine tetrahydrochloride (DAB). Slides were counterstained for 3.5 minutes in $1 \%$ aqueous neutral red (J.T. Baker Inc., Phillipsburg, NJ, R 747-03; Mesulam, 1978), buffered at $\mathrm{pH} 4.8$ with acetate buffer. The slides were washed in distilled $\mathrm{H}_{2} \mathrm{O}$, dehydrated in graded EtOH, cleared in xylene, coverslipped by using Permount, and studied using a Leitz Dialux microscope equipped with a drawing tube.

Slides were examined by using brightfield microscopy to locate and map labeled neurons located in the trigeminal ganglion injection site and anterograde labeling of neuron puncta in the auditory brainstem. Photomicrographs and camera lucida drawings were digitized and imported to Adobe Photoshop for labeling and contrast adjustment.

Electron microscopic evaluation. Three guinea pigs were processed for electron microscopy, two 24 hours after biocytin and one 4-6 days after BDA injections were made into ventral cochlear nucleus (VCN) as described above. 
Guinea pigs were deeply anesthetized with an intraperitoneal injection of sodium pentobarbital $(75 \mathrm{mg} / \mathrm{kg})$ and perfused transcardially with $600-800 \mathrm{ml}$ of $3 \%$ paraformaldehyde and $0.5 \%$ glutaraldehyde in $0.15 \mathrm{M}$ sodium cacodylate buffer $(\mathrm{pH} 7.35)$ at the rate of $50-70 \mathrm{ml} / \mathrm{min}$. The brainstem was removed and immersed in the same fixative for $2-4$ hours at $4^{\circ} \mathrm{C}$, followed by an overnight wash in cold phosphate-buffered saline (PBS), pH 7.2-7.4. Transverse sections through the auditory brainstem were obtained at a thickness of $60 \mu \mathrm{m}$ with a Vibratome (Pelco 101, St. Louis, MO). For enzymatic reaction to reveal biocytin and BDA label, the sections were first incubated for 2 hours in Avidin-D-HRP (Vector Laboratories, Inc. \#A-2004), dissolved in 1\% Triton X-100 (Sigma 9002-93-1) in $0.1 \mathrm{M}$ phosphate buffer, $\mathrm{pH}$ 7.4. The sections were then incubated for 8 minutes in $0.075 \% \mathrm{DAB}$ and $0.005 \% \mathrm{H}_{2} \mathrm{O}_{2}$ (Sigma, H-1009). The reacted sections were postfixed at room temperature for 1 hour in $0.2 \%$ osmium tetroxide in $0.15 \mathrm{M}$ cacodylate buffer, $\mathrm{pH}$ 7.35. Following osmication, the sections were washed in three 5-minute changes of cacodylate buffer, dehydrated in graded ethanols, and flatembedded in epoxy resin between sheets of ACLAR (Ted Pella, Redding CA; Embed 812, EMSciences, Fort Washington, PA). After polymerization, subdivisions of the cochlear nucleus were dissected from the plastic sections and glued to blank resin blocks with a cyanoacrylate adhesive (Borden Wonderbond, Borden, Columbus, $\mathrm{OH}$ ). Ninety-five-nm sections were cut with an ultramicrotome (Reichert Ultracut, Vienna, Austria), mounted onto precleaned nickel grids, counterstained with lead citrate and uranyl acetate, and examined with a JEOL EM-1200 electron microscope.

\section{Retrograde tracing using WGA-HRP and BDA}

Injections. For wheatgerm agglutinin-horseradish peroxidase (WGA-HRP; $\mathrm{n}=5)$, BDA $(\mathrm{n}=2)$, and fluorescent tracer $(n=4)$ injections, the left cochlear nucleus was approached from the posterior fossa and visualized by aspirating a small part of the overlying cerebellum. A glass micropipette filled with a solution of $2 \%$ WGA-HRP, or $10 \%$ BDA (MW 10,000, Molecular Probes, Eugene, OR) in phosphate-buffered saline $(\mathrm{pH} 7.4)$, was placed under visual control on the lateral surface of the DCN. After the micropipette placement, the brain was covered with warm mineral oil to prevent tissue desiccation and reduce brain pulsation. Evoked potentials in response to click stimulation were recorded as the electrode was advanced in a rostral-ventral direction (Shore and Nuttall, 1985). At a depth corresponding to the maximum-amplitude evoked potential, positive current (3-5 $\mu \mathrm{A}$, continuous for WGAHRP, fluorogold and fast blue, and pulsed 7 seconds on, 7 seconds off for BDA) was passed through the micropipette for 2-5 minutes. After the micropipette was removed, some neck muscle was applied to replace the volume of aspirated brain, dental cement was used to seal the opening, and the skin was sutured. The animal was allowed to recover.

Retrograde labeling. After the injections, 24 hours for WGA-HRP and 4-6 days for BDA were allowed for adequate neuron labeling. In some animals in which one fluorescent tracer was injected into the VCN, the skin overlying the jaw was injected with a second fluorescent tracer in order to label sensory cells in the trigeminal ganglion for comparison with cells labeled by VCN injec- tions. Animals were then perfused and tissue processed as described above for the light microscopic analysis of biocytin anterograde transport for HRP, or by incubating BDA-containing sections with avidin-conjugated fluorescent markers (Vector Labs, 1:50 in 0.1 M PBS, pH 8.2).

Neurons labeled by retrograde transport of WGA-HRP or BDA in the trigeminal ganglion were mapped by using a brightfield microscope equipped with a camera lucida drawing tube. The labeled cells in each section were counted manually. Cells with a distinctly labeled outline and either a relatively clear central nuclear zone or an almost homogeneous black labeling of the cytoplasm, which are criteria indicating that the major part of the cell was included in the section, were selected for mapping. For labeled cells, soma shape, size, and location in the ganglion were recorded. Soma size was measured by using a calibrated eyepiece micrometer without correction for tissue shrinkage which occurs during processing. Student's t-test was used to determine the significance level of cell size differences in different divisions of the ganglion. Fluorescent labeled cells were viewed by using a Nikon epifluorescence microscope with the appropriate filters for fluorogold, fast blue, rhodamine, and fluoroscine isothiocyanate (FITC) emission.

Controls for endogenous peroxidase activity. To control for the presence of endogenous peroxidase activity in trigeminal afferent neurons, trigeminal ganglia from two animals were fixed by vascular perfusion, sectioned serially at $30 \mu \mathrm{m}$, and processed according to the DAB technique without exposure to reagents containing exogenous HRP. Sections were then examined under bright- and darkfield illumination. No labeling was seen under these conditions.

Controls for nonspecific labeling. To control for the possibility that some of the visualized reaction product may have resulted from the nonspecific deposition of incubation medium components, several sections from each experimental animal were treated with medium lacking the chromogen DAB. To rule out the possibility that the visualized reaction product resulted from the nonenzymatic hydrolysis of an incubation medium component, several sections from each experiment were heated for 15-20 minutes at $90-100^{\circ} \mathrm{C}$ to inactivate the enzymes prior to incubation in the complete medium. No labeling was seen under these conditions.

\section{RESULTS \\ Anterograde labeling following injections into the trigeminal ganglion}

The biocytin and BDA injection sites in the trigeminal ganglion were characterized by a central core of labeled neurons that appeared to be completely filled with agent. Most cells around the injection site exhibited dense labeling. The reaction product was present in the form of small, evenly distributed cytoplasmic granules. The nucleus was clearly visible in most labeled neurons. Labeled axons emerged from the central core of the injection site.

Cochlear nucleus. Following survival periods of 24 hours for biocytin and 4-6 days for BDA injections, light microscopic examination revealed numerous labeled puncta or synaptic terminals in the ipsilateral magnocellular regions of $\mathrm{VCN}$, and in the surrounding marginal cell areas. The most dense concentration of puncta was in the 


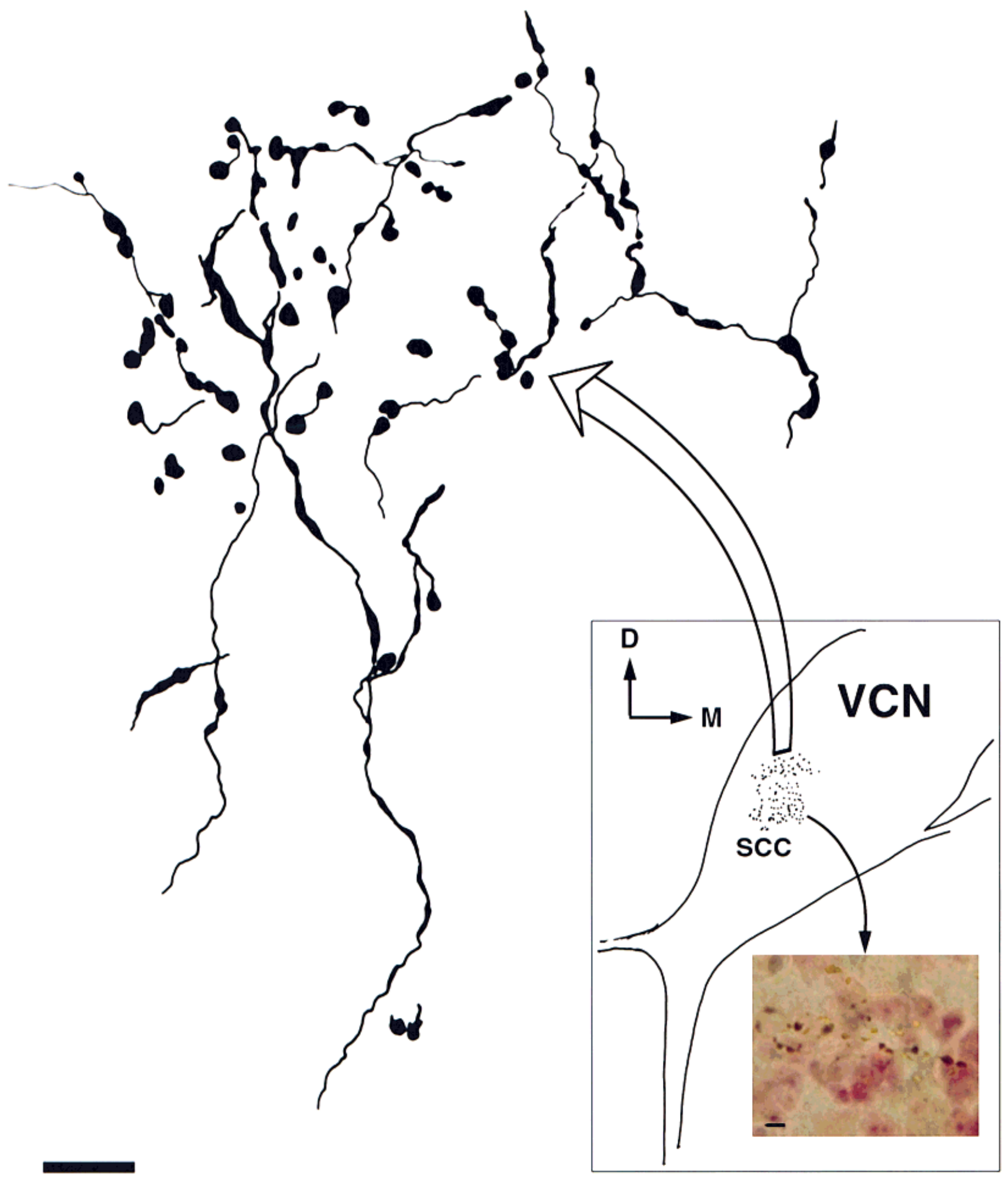

Fig. 1. Terminals from thin axons of the trigeminal ganglion end in the small cell cap (SCC) region of the anteroventral cochlear nucleus (AVCN). A transverse section (inset) of the ventral cochlear nucleus (VCN) is drawn, indicating the location of terminals by stippling. Large arrow points to an expanded drawing of some of these terminals at upper left. Small arrow points to photomicrograph at lower right, showing an expanded view of some of the terminals. The axons typically form boutons de passage. D, dorsal; M, medial. Large scale bar $=5 \mu \mathrm{m}$; small scale bar $=10 \mu \mathrm{m}$. 

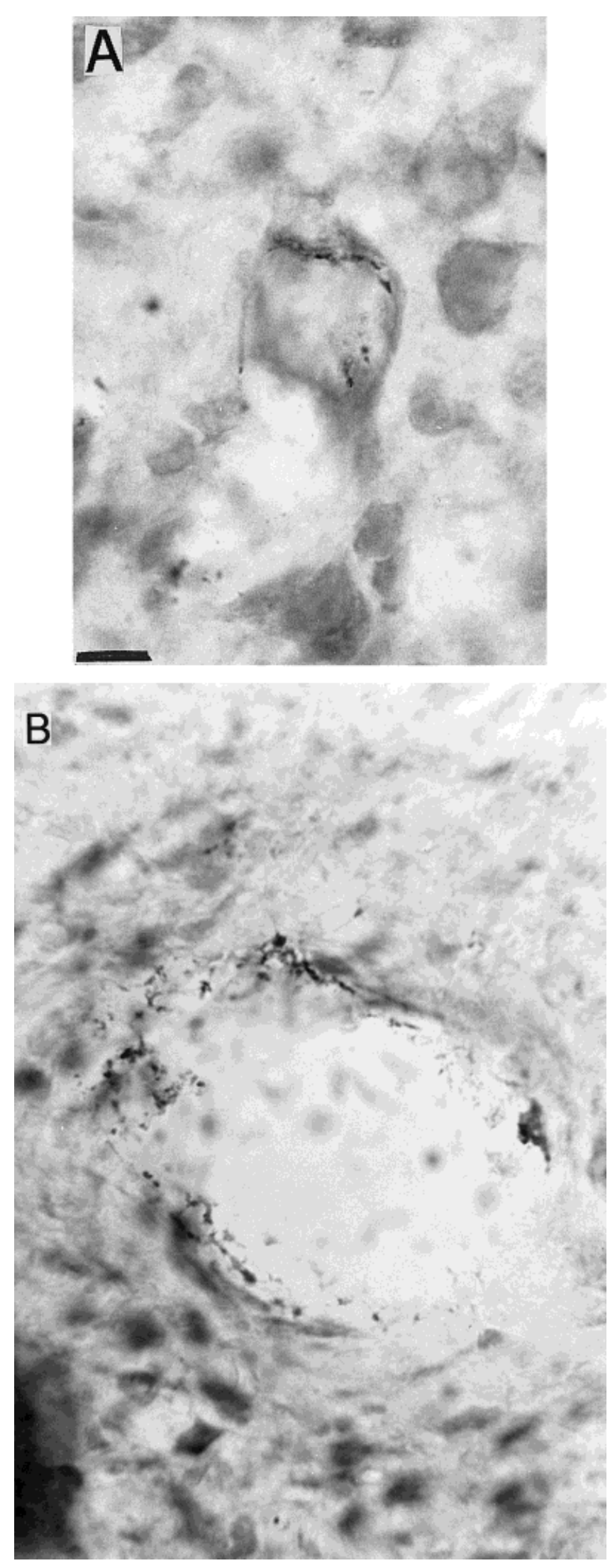

marginal cell area (or small cell cap) of the VCN in the form of beads or varicosities (Fig. 1). Labeled axons in this area were thin (around $1 \mu \mathrm{m}$ ), suggesting slow conduction velocities, and typically formed boutons de passage (Fig. 1). Puncta were also located on the lateral edges of the granule cell area.

In the magnocellular regions of anteroventral and posteroventral cochlear nucleus (AVCN and PVCN), labeled terminals tended to cluster towards the edges of the nucleus both medially and laterally. Puncta were seen both on cell bodies (Fig. 2A) and in the proximity of, or surrounding blood vessels (Fig. 2B). Labeling in the vicinity of blood vessels was also observed in the marginal cell area. Occasional labeling in the vicinity of blood vessels was also observed in the contralateral VCN.

EM examination of labeled terminals in the cochlear nucleus

Marginal cell area of VCN. Densely labeled terminals were observed synapsing on dendrites in the marginal cell area of the VCN (Fig. 3A,B). The terminals were often apposed to two or more dendrites (Fig. 3B). In some cases, there was evidence for asymmetric junctional thickening (Fig. 3A,B). Quantitative measurements of vesicles in one labeled terminal yielded average areas of $1,396 \mathrm{~nm}^{2}$, with an average roundness value of 0.92 . On this basis, vesicles were judged to be small, round, consistent with the classification of Cant and Morest (1979) and Cant (1993). No correction factors were applied for the outer margins of the vesicles being sometimes obscured by reaction product.

Magnocellular cell area of VCN. Two types of associations were observed in the magnocellular regions of VCN. Many labeled terminals were seen in close association with blood vessels. Less numerous labeled terminals were observed making axodendritic contacts, often on spines, or axosomatic contacts onto spherical bushy or globular bushy cells.

Trigeminal nucleus. Biocytin and BDA injections into the trigeminal ganglion resulted in dense anterograde labeling in the ipsilateral principal trigeminal nucleus and the sensory root of the trigeminal nerve. The diameters of labeled axons and terminal arborizations in the trigeminal nucleus were considerably larger (greater than $2 \mu \mathrm{m}$ ) than those labeled in the marginal cell area. Labeling in the trigeminal nucleus was not associated with blood vessels.

Superior olivary complex. After BDA injections into the trigeminal ganglion, terminal labeling was observed in ipsilateral "shell" regions (Vetter and Mugnaini, 1992; Warr et al., 1997) of the lateral superior olivary complex (LSO; Fig. 4), the lateral nucleus of the trapezoid body (LNTB), and the lateral periolivary area (LPO) rostral to LSO (Fig. 5).

Fig. 2. A: Brightfield micrograph of biocytin-labeled puncta on a cell in anteroventral cochlear nucleus (AVCN) 24 hours after an injection was made into the left trigeminal ganglion. This cell was located towards the medial border of AVCN. B: Brightfield micrograph of biocytin-labeled puncta surrounding the lumen of a blood vessel in the magnocellular region of posteroventral cochlear nucleus (PVCN). Scale bar $=10 \mu \mathrm{m}$ for A; $20 \mu \mathrm{m}$ for B. 

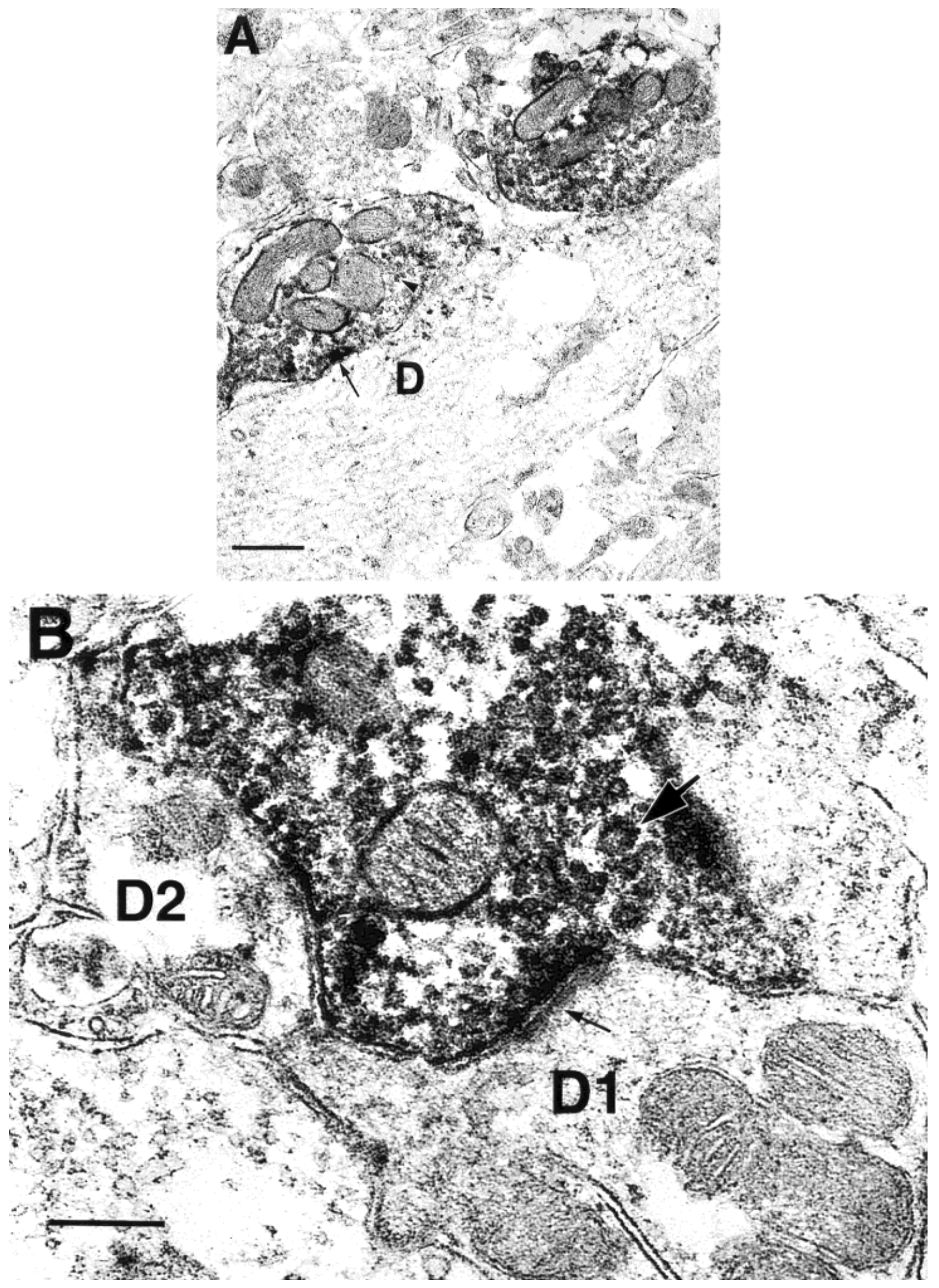

Fig. 3. Trigeminal ganglion fibers synapse on dendrites in the marginal cell area of anteroventral cochlear nucleus (AVCN). A: This electron micrograph shows asymmetric junctional thickening in a biotinylated dextran amine (BDA)-labeled terminal (arrowhead), apposed to a dendrite. The terminal contains mainly small, round ves- icles (arrowhead). B: A terminal apposed to two dendrites (D1 and D2) is shown. Asymmetric junctional thickening (small arrow) is evident. The terminals contained primarily small, round vesicles, although occasional, larger vesicles were seen (large arrow). Scale bars $=250 \mathrm{~nm}$. 

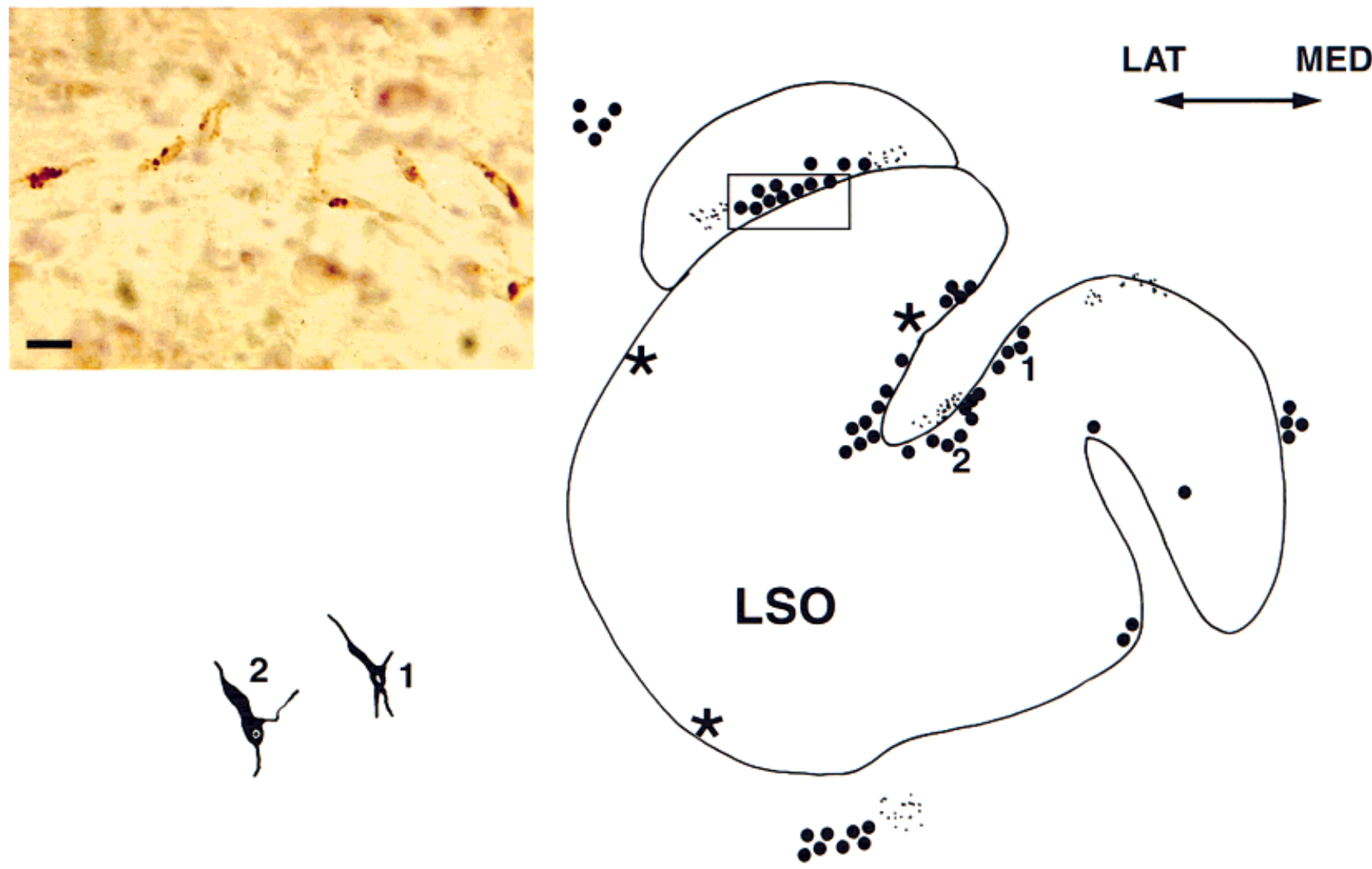

Fig. 4. Camera lucida drawings showing the locations of labeled cells in the "shell," or surrounding regions of the lateral superior olivary complex (LSO). Data from three sections are included. Some of the labeled cells (inset, color micrograph) contain reaction product in

their cytoplasm suggestive of retrograde uptake. Numbered cells are enlarged drawings of indicated labeled cells. Large dots indicate retrograde labeling; small dots indicate anterograde labeling; asterisks indicate labeled puncta around blood vessels. Scale bar $=20 \mu \mathrm{m}$.

\section{Retrograde labeling following injections into the trigeminal ganglion}

Cells exhibiting reaction product throughout the cytoplasm and dendrites were observed primarily in the ipsilateral motor trigeminal nucleus, raphe nuclei, and pontine nuclei of both sides. Fewer labeled cells were observed in the ipsilateral cochlear nucleus, superior olivary complex, and principal trigeminal nucleus (Figs. 4-6). Labeled cells in the cochlear nucleus were usually located in the ventral regions of AVCN and PVCN towards the center, whereas those in the LSO were located on the margins, in the "shell" regions (Figs. 4 and 6).

\section{Retrograde labeling following injections into the cochlear nucleus}

Histologic examination confirmed that WGA-HRP and BDA injections were localized to the VCN. As we reported previously (Shore et al., 1991, 1992; Shore and Moore, 1998), retrogradely labeled cells projecting to the VCN were found throughout the brainstem. In this investigation, we focused on labeled cells in the trigeminal ganglion.

Retrogradely labeled cells in the trigeminal ganglion. Injections of WGA-HRP, BDA, or fluorescent tracers into the VCN produced robust labeling of cells primarily in the ipsilateral trigeminal ganglion, but labeled cells were also observed on the contralateral side. The heaviest labeling was seen in the medial portion of the ganglion and at the origin of the ophthalmic nerve. Labeled cells were observed mostly on the medial side of the ophthalmic nerve. There were also numerous labeled cells laterally, in the posterior portion of the mandibular division of the ganglion. Fewer labeled cells were seen in the mid-medial and posteromedial portions of the trigeminal ganglia (Fig. 7A,B). Labeling after a cochlear injection with WGA-HRP (Fig. 7C,D), is restricted to the ophthalmic division.

The distribution of HRP-WGA- and BDA-labeled cells according to their maximal diameter indicates that the labeled cells in the ophthalmic division (Fig. 8A) were larger than in the mandibular division (Fig. 8B, $P<$ 05). Labeled cells in the ophthalmic division had maximal diameters ranging from 10 to $45 \mu \mathrm{m}$, with a mean of $20 \mu \mathrm{m}$. In contrast, labeled cells in the mandibular division had maximal diameters ranging from 10 to 28 $\mu \mathrm{m}$, with a mean of $12 \mu \mathrm{m}$. Most cells were densely labeled, with the reaction products appearing as small, evenly distributed cytoplasmic granules that created a 

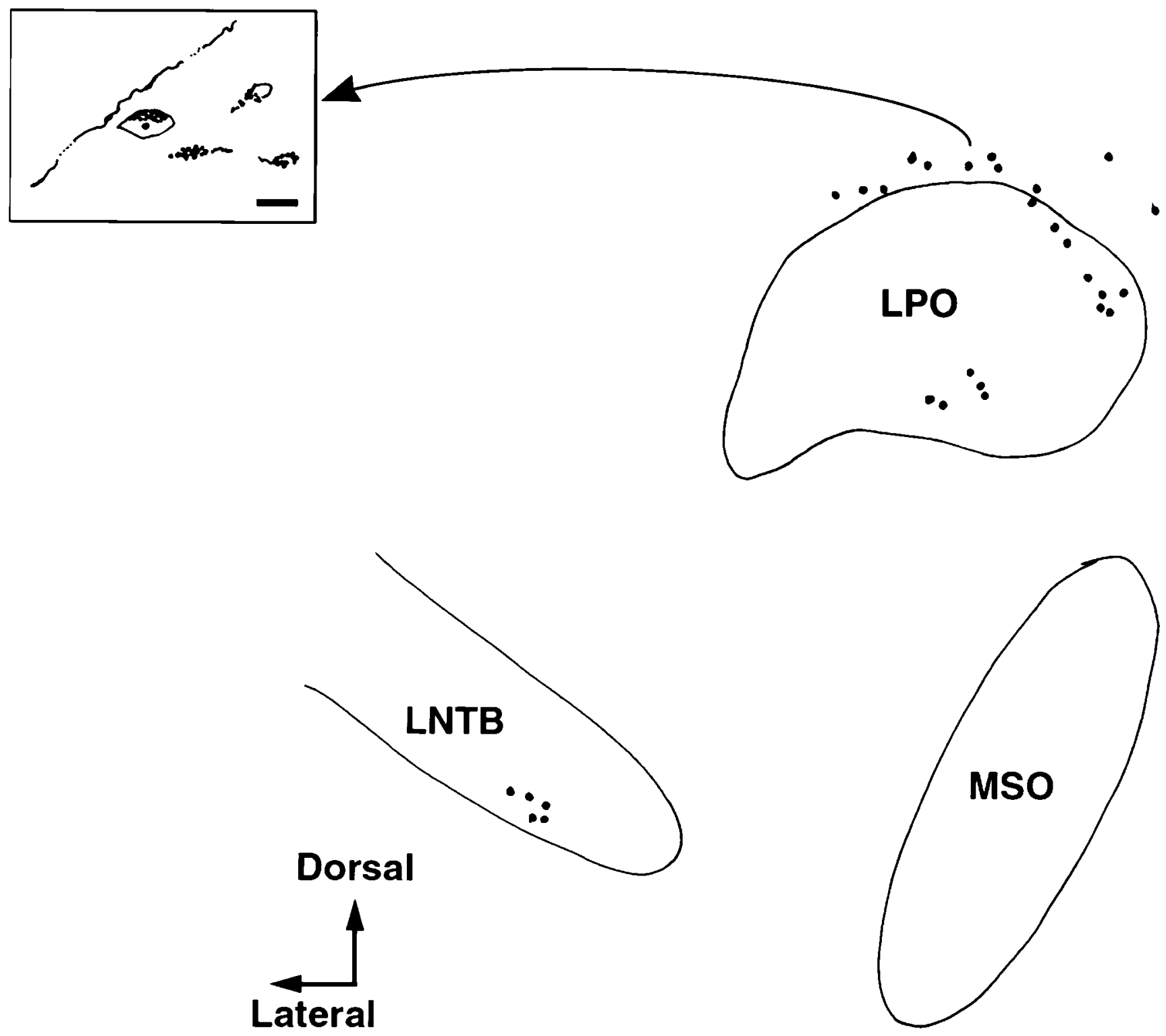

Fig. 5. Camera lucida drawings showing the locations of labeled cells in the lateral nucleus of the trapezoid body (LNTB) and RPO. The drawings in the upper left inset represent enlarged drawings of

stippled appearance. The nucleus was clearly visible in the majority of labeled neurons (Fig. 9). The labeled cells tended to be of two types: those having oval or elongated somata with two processes, or those with polygonal somata and three processes. The use of fluorescent tracers enabled us to inject one tracer into the VCN and compare the labeled cells with those labeled by an injection of second tracer into the skin of the mandible (Figs. 10 and 11). The cells labeled by VCN injections were usually smaller, with a smaller, less prominent nucleus than those labeled by skin injections, and demonstrated uneven surfaces (Figs. 10 and 11 , top panels). These surface irregularities may indicate terminal labeling, suggestive of a reciprocal projection. labeled cells in the lateral periolivary region (LPO). Large dots indicate retrograde labeling; small dots indicate anterograde labeling. MSO, medial superior olivary complex. Scale bar $=20 \mu \mathrm{m}$.

\section{DISCUSSION}

This study provides the first evidence that the trigeminal ganglion sends a projection to auditory areas of the medulla and pons, primarily the cochlear nucleus and LSO. There is some indication that these projections may be reciprocal.

\section{Trigeminal ganglion projections to the cochlear nucleus}

As in other primary sensory systems, the cochlear nuclei are known to receive efferent information from higher auditory centers. These pathways run parallel to the ascending pathways, presumably to enhance or attenuate incoming sensory information from the auditory nerve. 


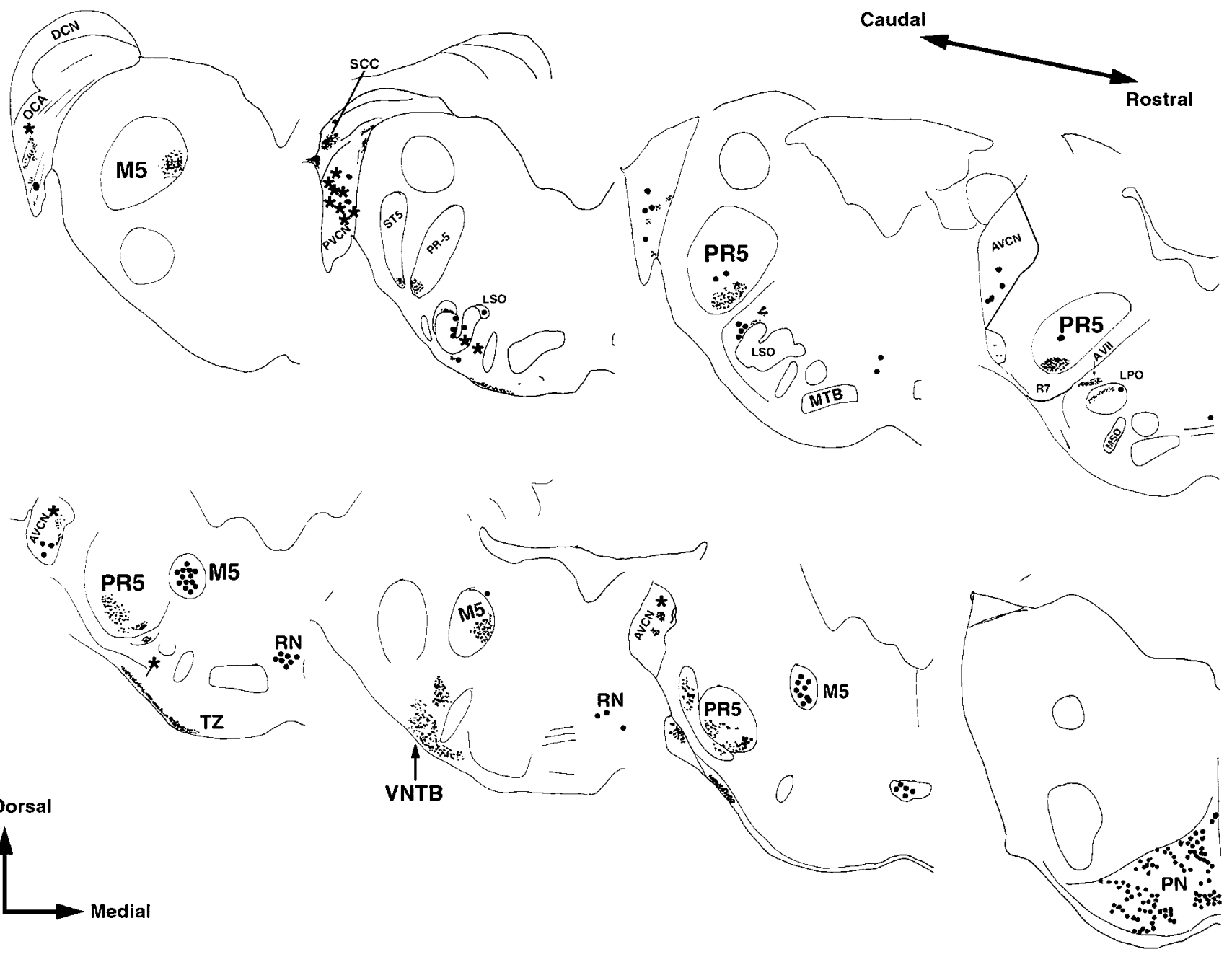

Fig. 6. Camera lucida reconstructions of transverse sections through the brainstem of one guinea pig following a biotinylated dextran amine (BDA) injection into the left trigeminal ganglion. Anterograde labeling is shown by stippling; retrograde labeling is shown by large dots; asterisks indicate anterograde labeling around blood vessels. Examples of retrograde labeling (large dots) are seen primar- ily in pontine nucleus (PN), motor nucleus of the fifth cranial (trigeminal) nerve (M5), and raphe nucleus (RN). More sparse retrograde labeling is seen in principal trigeminal nucleus (PR5), lateral superior olivary complex (LSO), and anteroventral cochlear nucleus (AVCN). For other abbreviations, see list.
Because many of the neurons projecting out of the VCN receive descending information from their target neurons (Covey et al., 1984; Spangler and Warr, 1991; Winter et al., 1989; Spangler et al., 1987; Shore et al., 1991, 1992), some consider these projections to have a feedback function. Whereas modulatory interactions of heterosensory pathways have been described in higher nuclei of the central nervous system (Aitkin et al., 1978), only in recent years has it become apparent that input from nonauditory sensory systems also impinges on first-order auditory neurons. In the present study, injections of anterograde tracers into the trigeminal ganglion produced the most dense labeling in the marginal cell (including small cell cap) region of the cochlear nucleus. The labeled axons in this area were thin (around $1 \mu \mathrm{m}$ ), suggesting slow conduction velocities. Their axodendritic terminals, containing small spherical vesicles, are likely to be excitatory (Ostapoff and Morest, 1991). Other excitatory inputs to this area include the cuneate nucleus, dorsal column nuclei, interpolar and caudal spinal trigeminal nuclei (Itoh et al., 1987; Wolff and Kunzle, 1997), which form possible glutamatergic synapses with granule cells (Wright and Ryugo, 1996). Immunocytochemical studies of the cochlear nucleus also reveal puncta that stain for substance $\mathrm{P}$, a known sensory neurotransmitter (Adams, 1993), whose locations coincide terminations of projections from the somatosensory regions described by Itoh et al. (1986), thus implicating substance $\mathrm{P}$ as another possible neurotransmitter of those projections. Substance P is involved in the cochlear projection from the trigeminal ganglion (Vass et al., 1997, 1998b) and thus may also be the neurotransmitter of the trigeminal ganglion-cochlear nucleus projection.

Injections of retrograde tracer into one cochlear nucleus produced labeling in both trigeminal ganglia, although the contralateral side was sparsely labeled. Contralateral innervation has also been reported for cerebral blood vessels 

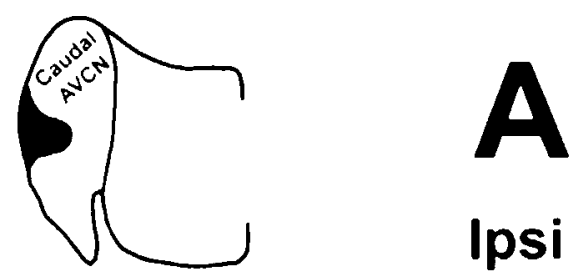

Ipsi
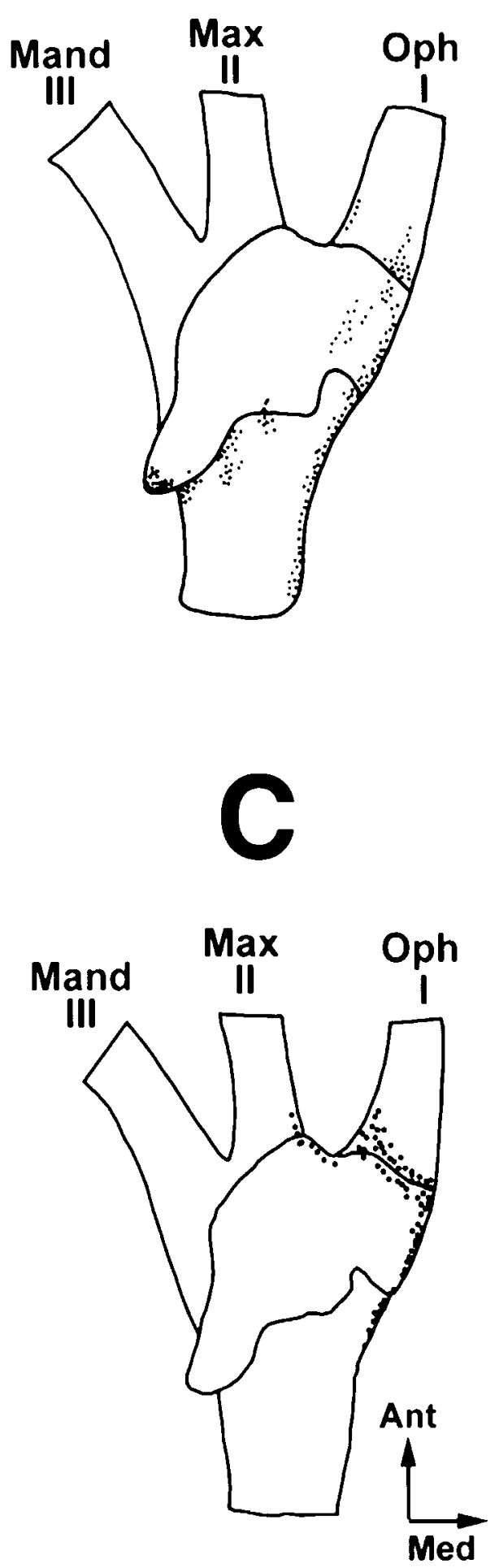

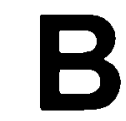

Contra
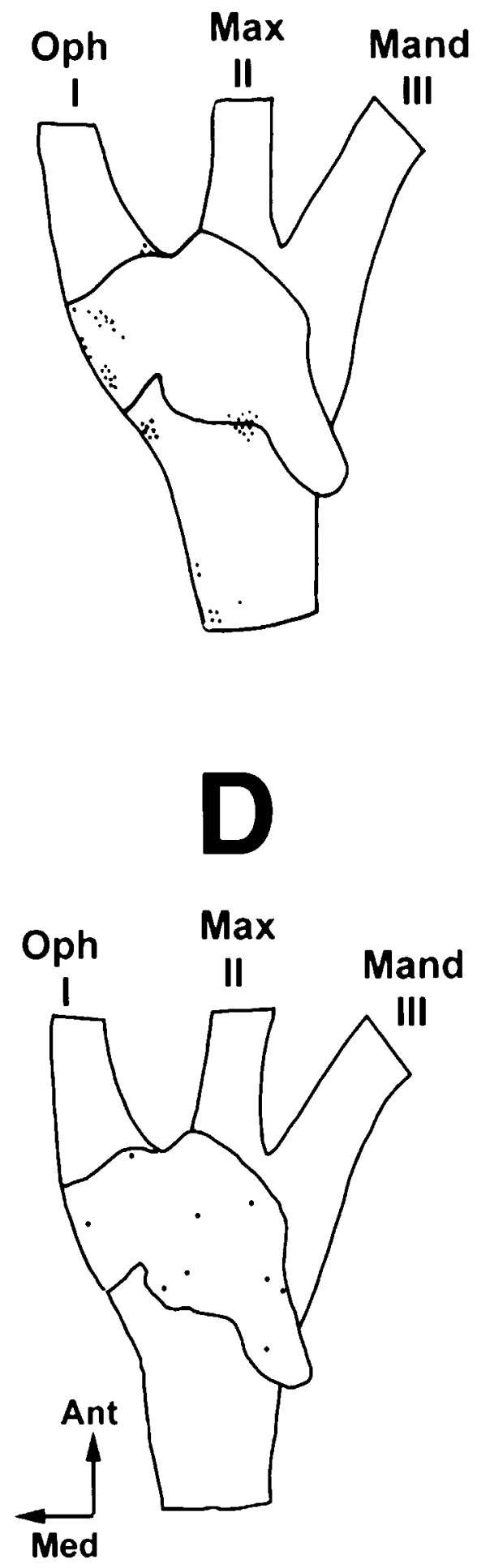


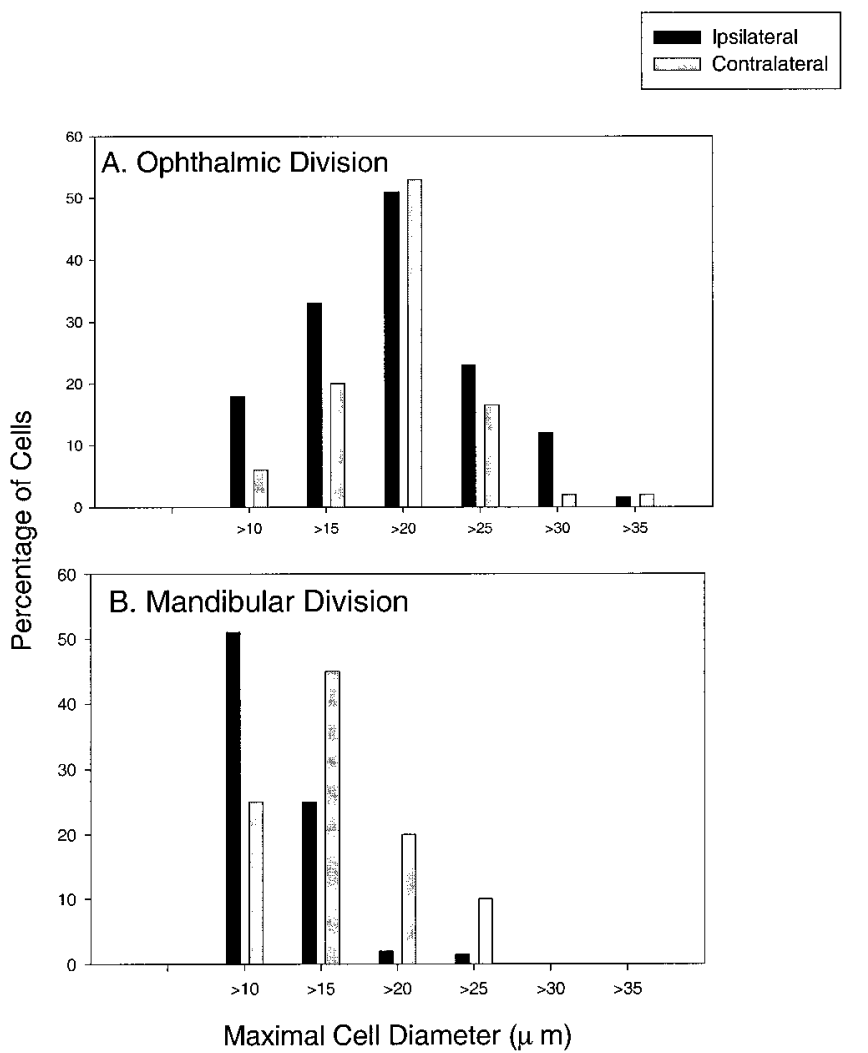

Fig. 8. Distribution of wheatgerm agglutinin-horseradish peroxidase (WGA-HRP) and biotinylated dextran amine (BDA)-labeled cells in the trigeminal ganglion according to their maximal soma diameters. These data represent a random sample taken from 5 ganglia. A: Ophthalmic division; $\mathrm{n}=222$. B: Mandibular division; $\mathrm{n}=148$.

(Edvinsson et al., 1989) and cochlear blood supply (Vass et al., 1997, 1998b). As shown for the projection from the trigeminal ganglion to the cochlea by using WGA-HRP (Vass et al., 1997), two types of cells, bipolar and multipolar, comprise the projection from the trigeminal ganglion to the cochlear nucleus. Both cell types are located in the same region of the ganglion (ophthalmic) that projects to the cochlea, as well as a restricted part of the mandibular division. Cells of similar size and shape, with two or three processes, have also been observed to innervate cerebral blood vessels (Moskowitz, 1984).

The cells labeled by mandibular skin and cochlear nucleus injections in this study indicate that the cells projecting to the cochlear nucleus are smaller than the sen-

Fig. 7. Schematic of horizontal sections through the trigeminal ganglia of one representative animal after a $2 \%$ wheatgerm agglutinin-horseradish peroxidase (WGA-HRP) injection was made into the ventral cochlear nucleus (VCN). The injection site is shown at upper left. A: Ipsilateral (Ipsi) trigeminal ganglion. B: Contralateral (Contra) trigeminal ganglion. Each dot represents a single labeled neuron, and data are taken from 3 consecutive sections. C: Schematic horizontal section through the ipsilateral trigeminal ganglion, and (D) the contralateral trigeminal ganglion after a $\%$ WGA-HRP injection was made into the cochlea (reproduced from Vass et al., 1997, with permission). For abbreviations, see list.
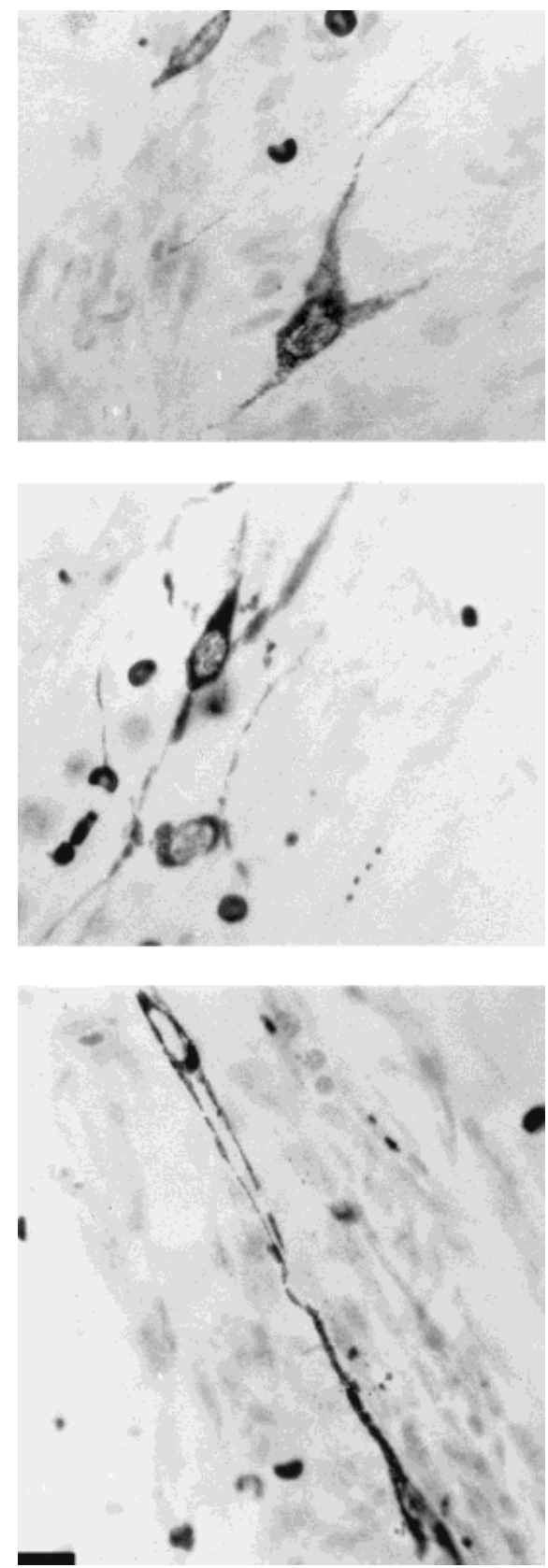

Fig. 9. Brightfield photomicrograph of wheatgerm agglutininhorseradish peroxidase (WGA-HRP)-labeled cell bodies in the ophthalmic division of the ipsilateral trigeminal ganglion after injection into the cochlear nucleus. The cell bodies shown here are polygonal with three processes (top), or elongated with two processes (middle and bottom). Scale bar $=20 \mu \mathrm{m}$.

sory cells innervating the skin overlying the mandible. The presence of terminal labeling on the surface of the cochlear nucleus-projecting cells indicates the possibility of this projection being reciprocal.

\section{Trigeminal ganglion projections to the LSO}

The trigeminal ganglion, in contrast to other somatosensory pathways, innervates both neurons and blood ves- 


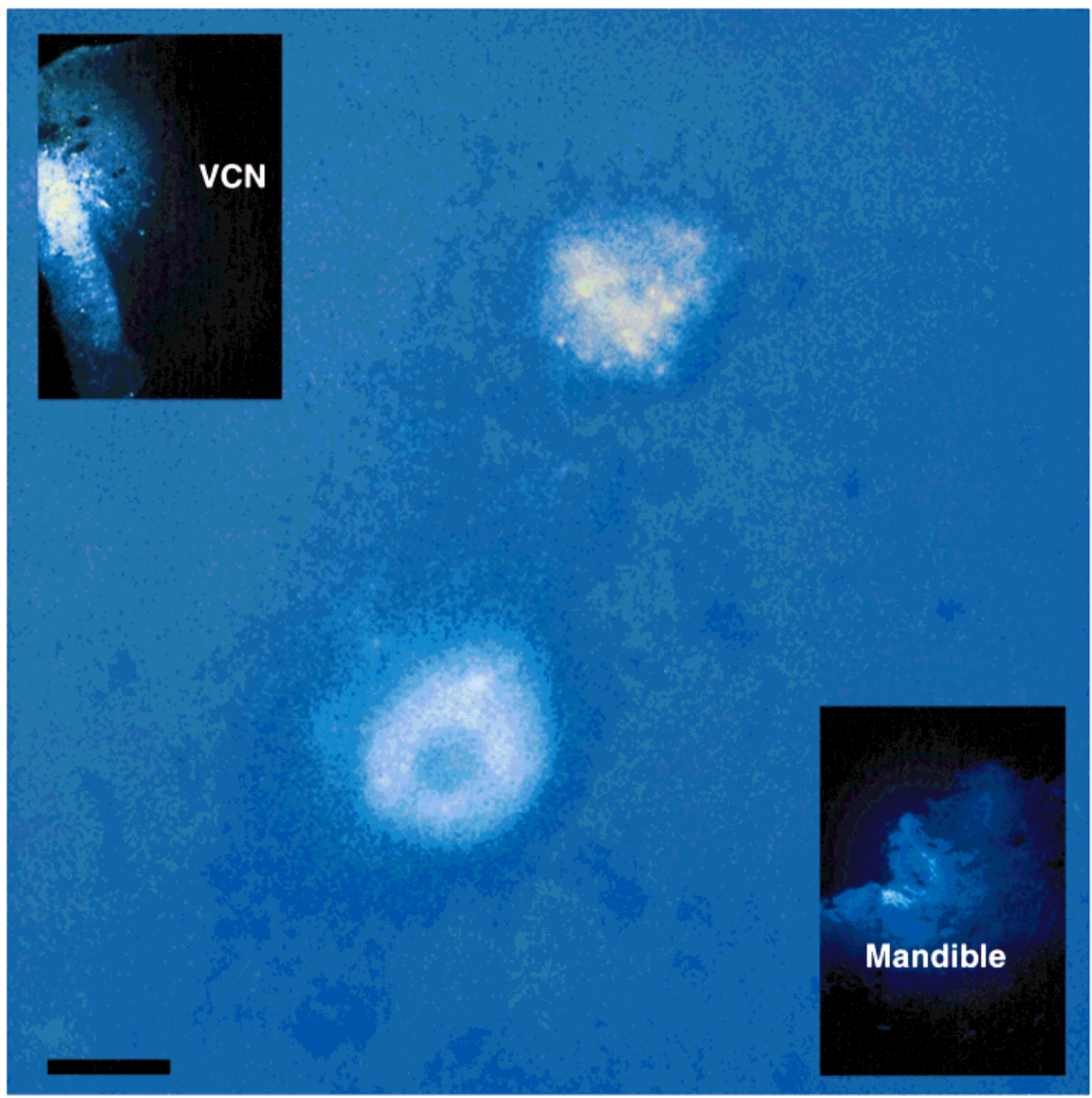

Fig. 10. Photomicrographs of injection sites (insets) and individual trigeminal ganglion somata filled by retrograde labeling (main body of micrograph). The neurons were labeled 1 week after fluorogold and fast-blue were injected into the cochlear nucleus and the skin overlying the mandible, respectively. The fluorogold-labeled neuron

sels in the cochear nucleus, and "shell" regions of LSO which are known to send projections to the cochlea (Vetter and Mugnaini, 1992; Warr et al., 1997). The small cell cap region of the cochlear nucleus, which is heavily innervated by the trigeminal ganglion, is also innervated by type II spiral ganglion cells. It is also innervated by collaterals of the olivocochlear system which project to cochlear hair cells and type I auditory nerve fibers (Brown and Benson, 1992; Brown, 1993; Benson et al., 1996; Ye et al., 1999). In addition, the trigeminal ganglion innervates both the auditory and vestibular portions of the labyrinth (Vass et al., 1997, 1998). Because the trigeminal ganglion projects to olivocochlear regions of the LSO as well as to the small cell cap region, which forms a reciprocal connection with olivocochlear neurons (Brown and Benson, 1992; Brown, 1993; projecting to the cochlear nucleus (top) has an irregular surface, perhaps indicating terminal endings, whereas the fast-blue-labeled neuron (bottom) projecting to the mandible has a prominent, enlarged nucleus. Scale bar $=25 \mu \mathrm{m}$.

Benson et al., 1996; Ye et al., 1999), we may speculate that this projection could form part of the olivocochlear feedback system.

\section{Function of somatosensory input to the auditory brainstem}

Physiological studies demonstrate that electrical stimulation of the dorsal column and trigeminal nuclei usually inhibits, but can also excite cells in the superficial and deep layers of DCN and VCN (Saade et al., 1989; Young et al., 1995). The inhibition to DCN neurons is produced through excitation of cells in the granular regions, which in turn modify (inhibit) the activity of principal cells in the DCN (Young et al., 1995). Tactile manipulation of the pinna likewise can inhibit DCN neurons, suggesting that 


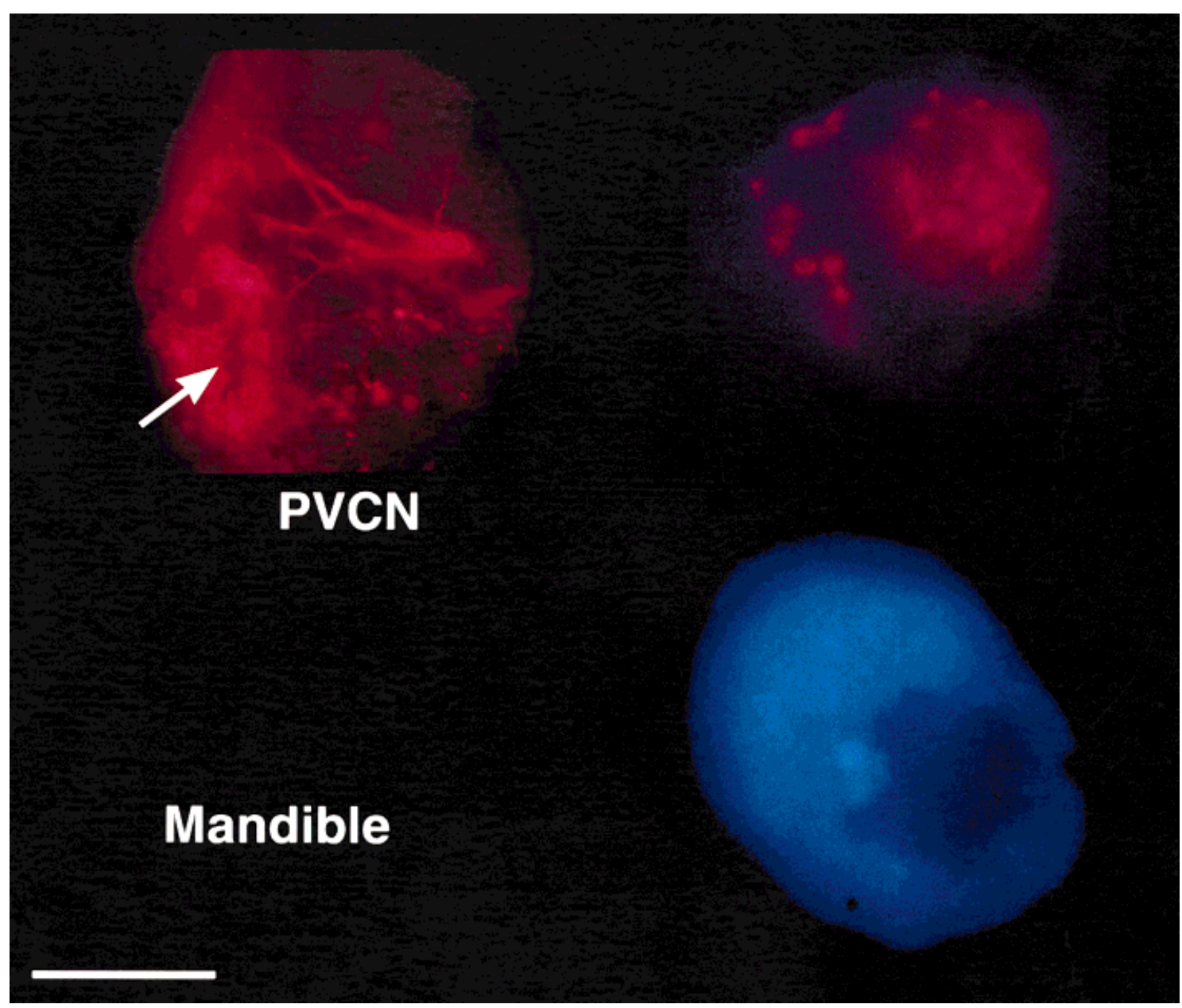

Fig. 11. An individual trigeminal ganglion neuron (red cell, top, right) is filled by retrograde labeling 6 days after an injection of fluororuby into the posteroventral cochlear nucleus (left column of micrograph). The injection site (arrow) shows deposits of fluororuby in lateral posteroventral cochlear nucleus (PVCN) with an adjacent octopus cell to the right which was filled by spread of the injection. The blue cell shown on bottom right is a cell filled by retrograde labeling

some of the cells stimulated electrically are those which represent the pinna and back of the head (Young et al., 1995). Thus, brainstem somatosensory input concerning pinna position may provide sound localization information to DCN cells.

Furthermore, the ophthalmic portion of the trigeminal ganglion also innervates extraocular muscles (Aigner et al., 1997). This raises another interesting possibility that these connections might be involved in vestibulo-ocular reflexes. Direct connections from the vestibular end organs to the cochlear nucleus have indeed been demonstrated (Kvetter and Perachio, 1989), as well as direct primary projections from the trigeminal ganglion to the lateral and superior vestibular nuclei (Pfaller and Arvidsson, 1988). Pfaller and Arvidsson (1988), by using HRPWGA injections into the trigeminal and dorsal root ganglia of the rat, observed terminal labeling along the medial edge of the VCN after injections into the $\mathrm{C} 2$ dorsal root ganglion but not after injections into the trigeminal gan-
6 days after the skin overlying the mandible was injected with fast blue (injection site not shown). The fluororuby-labeled neuron projecting to the PVCN has an irregular surface, similar to that shown in Fig. 10, perhaps indicating terminal endings, whereas the fast-bluelabeled neuron, projecting to the mandible, has a prominent, enlarged nucleus. Scale bar $=20 \mu \mathrm{m}$.

glion. It is possible that species, tracer, and survival-time differences could account for the disparity in findings.

The present study demonstrates that the regions of the trigeminal ganglion, which innervate the cochlear nucleus, overlap the regions that innervate both the cochlea and the middle ear: The ophthalmic division innervates the cochlea, and the mandibular region innervates the middle ear (Vass et al., 1997). The intriguing possibility therefore exists of a role for the trigeminal ganglion in the middle ear reflex. Support for this hypothesis is provided by the finding that cutaneous stimulation of the periorbital and external ear regions can evoke the middle ear reflex (Moller, 1975). The ascending limb of this reflex arc may be trigeminal input from the external auditory meatus (Folan-Curran et al., 1994). The first central relay station of the middle ear reflex is the VCN, which sends a projection bilaterally to the motor neurons of the tensor tympani and stapedius muscles located in the trigeminal and facial nuclei, respectively (Itoh et al., 1986; Rouiller et 
al., 1989). Thus, the trigeminal ganglion, activated by cutaneous stimulation in the region of the external ear, may modulate the activity of neurons in the VCN, which in turn project to motor neurons of the tensor tympani and stapedius. Because we have shown that the trigeminal ganglion projects to the middle ear, the cochlea and the VCN (Vass et al., 1997, 1998, and present study), modulation of the middle ear reflex could occur through direct trigeminal ganglion projections to the VCN and middle ear muscles. The projection may also be involved in central or "somatic" tinnitus, which can be initiated or modified by somatic stimulation of the head and neck region (Lockwood et al., 1998).

Finally, the observation, after biocytin injections into the trigeminal ganglion, that many of the labeled puncta in the VCN and LSO were located around the lumina of blood vessels, suggests an involvement of this pathway in the regulation of blood flow or metabolism in the cochlear nucleus and superior olivary complex. Stimulation of the trigeminal ganglion results in changes in cochlear and in cerebral blood flow (Vass et al., 1995; Goadsby et al., 1997; Lambert et al., 1997). Additionally, in peripheral and central blood vessels, administration of capsaicin, which stimulates release of substance $P$, produces sustained vasodilatation, increased vascular permeability (Jansco, 1992), and an increase in cochlear blood flow (Vass et al., 1994). In cerebral circulation, substance P-containing neurons may be associated with headache pain or reactions to trauma such as breakdown of the blood-brain barrier (Duckles and Buck, 1982). In the cochlea, the trigeminal ganglion may play a role in the pathophysiology of Menieres disease (Vass et al., 1998b).

Trigeminal input to the cochlear nucleus and other auditory brainstem neurons could have a great impact on the metabolism and function of cochlear nucleus neurons if it targets both the neurons and their vascular supply. Our anatomical characterization of this projection will set the stage for detailed functional studies of this potentially important projection. Our findings provide a unique opportunity to study the relationship between cochlear and cochlear nucleus innervation because tracer injections into the trigeminal ganglion also produce labeling in the cochlear vasculature (Vass et al., 1997). Because changes in peripheral hearing structures that occur with deafness may affect the structure of central auditory neurons, then pathological changes in innervation from peripheral somatosensory structures could also profoundly affect auditory functions requiring multisensory input, such as the localization of the body in space.

\section{ACKNOWLEDGMENTS}

We thank Tom Carey for many helpful suggestions over the course of this study and Don Godfrey for valuable comments on the manuscript.

\section{LITERATURE CITED}

Adams JC. 1993. Non-primary inputs to the cochlear nucleus visualized using immunocytochemistry. In: Merchan MA, Juiz JM, Godfrey DA, Mugnaini E, editors. The mammalian cochlear nuclei: organization and function. New York: Plenum.

Aigner M, Lukas JR, Denk M, Mayr R. 1997. Sensory innervation of the guinea pig extraocular muscles: a $1,1^{\prime \prime}$-dioctadecyl-3,3,3"3"-tetramethylindocarbocyanine perchlorate tracing and calcitonin gene- related peptide immunohistochemical study. J Comp Neurol 380: $16-22$.

Aitkin LM, Dickhaus H, Schult W, Zimmerman M. 1978. External nucleus of inferior colliculus: auditory and spinal somatosensory afferents and their interactions. J Neurophysiol 41:837-847.

Aitkin LM, Kenyon CE, Philpott P. 1981. The representation of the auditory and somatosensory systems in the external nucleus of the cat inferior colliculus. J Comp Neurol 196:25-40.

Benson TE, Berglund AM, Brown MC. 1996. Synaptic input to cochlear nucleus dendrites that receive medial olivocochlear synapses. J Comp Neurol 365:27-41.

Brown MC. 1993. Fiber pathways and branching patterns of biocytinlabeled olivocochlear neurons in the mouse brainstem. J Comp Neurol 337:600-613.

Brown MC, Benson TE. 1992.Transneuronal labeling of cochlear nucleus neurons by HRP-labeled auditory nerve fibers and olivocochlear branches in mice. J Comp Neurol 321:645-665.

Chalupa LM, Rhoades RW. 1977. Responses of visual, somatosensory, and auditory neurones in the golden hamster's superior colliculus. J Physiol (Lond) 270:595-626.

Covey E, Jones DR, Casseday JH. 1984. Projections from the superior olivary complex to the cochlear nucleus in the tree shrew. J Comp Neurol 226:289-305.

Drager UC, Hubel DH. 1976. Topography of visual and somatosensory projections to mouse superior colliculus. J Neurophysiol 39:91-101.

Duckles SP, Buck SH. 1982. Substance P in the cerebral vasculature: depletion by capsaicin suggests a sensory role. Brain Res 245:171-174.

Edvinsson L, Hara H, Uddman R. 1989. Retrograde tracing of nerve fibers to the rat middle cerebral artery with True Blue: co-localization with different peptides. J Cerebr Blood Flow Metab 9:212-218.

Folan-Curran J, Kickey K, Monkhouse WS. 1994. Innervation of the rat external auditory meatus: a retrograde tracing study. Somatosen Motor Res 11:65-68.

Goadsby PJ, Knight YE, Hoskin KL, Butler P. 1997. Stimulation of an intracranial trigeminally-innervated structure selectively increases cerebral blood flow. Brain Res 751:247-252.

Itoh K, Nomura S, Konishi A, Yasui Y, Sugimoto T, Mizuno N. 1986. A morphological evidence of direct connections from the cochlear nuclei to tensor tympani motoneurons in cat: a possible afferent limb of the acoustic middle ear reflex pathways. Brain Res 375:214-219.

Itoh K, Kamiya H, Mitani A, Yasui Y, Takada M, Mizuno N. 1987. Direct projections from the dorsal column nuclei and the spinal trigeminal nuclei to the cochlear nuclei in the cat. Brain Res 400:145-150.

Jansco G. 1992. Pathobiological reactions of C-fibre primary sensory neurones to peripheral nerve injury. Exp Physiol 77:405-431.

Killackney HP, Erzurumlu RS. 1981. Trigeminal projections to the superior colliculus of the rat. J Comp Neurol 201:221-242.

Kvetter GA, Perachio AA. 1989. Projections from the sacculus to the cochear nuclei in the Mongolian gerbil. Brain Behav Evol 34:193-200.

Lambert GA, Michalicek J, Regaglia F. 1997. Responses of the dural circulation to electrical stimulation of the trigeminal ganglion in the cat. Clin Exp Pharm Physiol 24:377-390.

Lockwood AH, Salvi RJ, Coad Ml, Towsley ML, Wack DS, Murhpy BW. 1998. The functional neuroanatomy of tinnitus: evidence for limbic system links and neural plasticity. Neurology 50:114-120.

Mesulam MM. 1978. Tetramethyl benzidine for horseradish peroxidase neurochemistry: a non-carcinogenic blue reaction-product with a superior sensitivity for visualizing neural afferents and efferents. J Histochem Cytochem 26:106-117.

Møller A. 1975. The acoustic middle ear reflex. In: Keidel WD, Neff WD, editors. Handbook of sensory physiology: auditory system, vol VII. Berlin: Springer. p 519-548.

Moskowitz MA. 1984. The neurobiology of vascular head pain. Ann Neurol 16:157-168.

Ostapoff EM, Morest DK. 1991. Synaptic organization of globular bushy cells in the ventral cochlear nucleus of the cat: a quantitative study. J Comp Neurol 314:598-613.

Pfaller K, Arvidsson J. 1988. Central distribution of trigeminal and upper cervical primary afferents in the rat studied by anterograde transport of horseradish peroxidase conjugated to wheat germ-agglutinin. J Comp Neurol 268:91-108.

Rice JJ, May BJ, Spirou GA, Young ED. 1992. Pinna-based spectral cues for sound localization in cat. Hearing Res 58:132-152.

Rouiller EM Capt M, Dolivo M, De Ribaupierre F. 1989. Neuronal organi- 
zation of the stapedius reflex pathways in the rat: a retrograde HRP and viral transneuronal tracing study. Brain Res 476:21-28.

Saade NE, Frangieh AS, Atweh SF, Jabbur SJ. 1989. Dorsal column input to cochlear neurons in decerebrate-decerebellate cats. Brain Res 486: 399-402.

Shore SE, Moore JK. 1998. Sources of input to the cochlear granule cell region in guinea pig. Hear Res 116:33-42.

Shore SE, Nuttall AL. 1985. The effects of cochlear hypothermia on compound action potential tuning. J Acoust Soc Am 77:590598.

Shore SE, Helfert RH, Bledsoe SC Jr, Altschuler RA, Godfrey DA. 1991. Descending projections to the guinea pig cochlear nucleus. Hearing Res 52:255-268.

Shore SE, Helfert RH, Bledsoe SC Jr, Altschuler RA, Godfrey DA. 1992. Connections between the cochlear nuclei in the guinea pig. Hearing Res 62:16-26.

Spangler KM, Warr WB. 1991. The descending auditory system. In: Altschuler RA, Bobbin RP, Clopton BM, Hoffman DW, editors. Neurobiology of hearing. The central auditory system. New York: Raven Press. p 27-45.

Spangler KM, Cant, NB, Henkel CK, Farley GR, Warr WB. 1987. Descending projections from the superior olivary complex to the cochlear nucleus of the cat. J Comp Neurol 259:452-465.

Vass Z, Bari F, Jansco G. 1994. Possible involvement of capsaicin-sensitive sensory nerves in the regulation of cochlear blood flow in the guinea pig. Acta Otolaryngol (Stockh) 114:156-161.

Vass Z, Nuttall AL, Coleman JKM, Miller JM. 1995. Capsaicin-induced release of substance $\mathrm{P}$ increases cochlear blood flow in the guinea pig. Hear Res 89:86-92.

Vass Z, Shore SE, Nuttall AL, Miller JM, Brechtelsbauer PB. 1997. Tri- geminal ganglion innervation of the cochlea-a retrograde transport study. Neuroscience 79:605-615.

Vass Z, Shore SE, Nuttall AL, Miller JM. 1998a. Direct evidence of trigeminal innervation of the cochlear blood vessels. Neuroscience 84: $559-567$.

Vass Z, Shore SE, Nuttall AL, Miller JM. 1998b. Endolymphatic hydrops reduces trigeminal innervation to inner ear vasculature. Exp Neurol 151:241-248.

Vetter DE, Mugnaini E. 1992. Distribution and dendritic reatures of three groups of rat olivocochlear neurons. Anat Embryol 185:1-16.

Warr WB, Beck Boche J, Neely ST. 1997. Efferent innervation of the inner hair cell region: origins and terminations of two lateral olivocochlear systems. Hear Res 108:89-111.

Weinberg RJ, Rustioni A. 1987. A cuneocochlear pathway in the rat. Neuroscience 20:209-219.

Winter IM, Robertson D, Cole KS. 1989. Descending projections from auditory brainstem nuclei to the cochlea and cochlear nucleus of the guinea pig. J Comp Neurol 280:143-157.

Wolff A, Kunzle H. 1997. Cortical and medullary somatosensory projections to the cochlear nucleus complex in the hedgehog tenrec. Neurosci Let 221:125-128.

Wright DD, Ryugo DK. 1996. Mossy fiber projections from the cuneate nucleus to the cochlear nucleus in the rat. J Comp Neurol 365:159172.

Ye Y, Machado DG, Kim DO. 1999. Projections of the marginal shell of the anteroventral cochlear nucleus to olivocochlear neurons in the cat. Abstract 22nd ARO, 584, p. 148.

Young ED, Nelken I, Conley RA. 1995. Somatosensory effects on neurons in dorsal cochlear nucleus. J Neurophysiol 73:743-765. 